\title{
Quantifying \\ Benthic Exchange of Fine Sediment via Continuous, Noninvasive Measurements of \\ Settling Velocity and Bed Erodibility
}

BY CARL T. FRIEDRICHS, GRACE M. CARTWRIGHT, AND PATRICK J. DICKHUDT

Benthic exchange of fine sediment has major implications for the structure and function of shelf and estuarine environments. Globally, the transport of particulate organic carbon from the land to the sea is closely associated with transport of mud (McKee et al., 2004). Fine sediment transport is particularly important to the occurrence of coastal eutrophication and to the fate and burial of pollutants because nutrients and contaminants tend to adsorb preferentially onto small particles (Lee and Wiberg, 2002). However, progress in characterizing muddy benthic exchange dynamics in the past has been slow because erosion and settling properties of fine sediment remain difficult to predict. Thanks in part to the availability of continuous, noninvasive measurements, initial results from the CoOP Multidisciplinary Benthic Exchange Dynamics (MUDBED) project strongly suggest that depositional events play a key role in perturbing bed erodibility and particle settling velocity away from more stable, biologically mediated values.

Bed erodibility and settling velocity are among the most sensitive, yet poorly constrained, parameters in fine sediment transport models (Harris et al., 2005). Bed erodibility limits the mass of mud suspended, while settling velocity determines how far mud travels. Both of these parameters can vary strongly in time and space, and both are directly affected by biological processes. Contributing to uncertainties regarding parameterization of settling velocity and bed erodibility are the difficulty, disturbance, and expense associated with their field measurement (e.g., Dyer et al., 1996; Sanford, 2006). Video settling tubes, for example, damp ambient currents and may be biased toward larger, more optically responsive particles. No field-based seabed erosion devices can remotely collect extended time series, and all are disruptive and labor intensive.

New field applications of small, turbulence-resolving acoustic current meters are providing insights into fine sediment erodibility and settling as part of the MUDBED project. Although originally designed for velocity measurement only, the backscatter associated with acoustic current sensors can be easily calibrated for suspended sediment concentration (Holdaway et al., 1999). In addition, acoustic returns can easily be used to track local seabed elevation. Acoustic backscatter methods are noninvasive and resistant to biofouling, and backscatter measurements by highresolution velocimeters are inherently temporally and spatially collocated with turbulent velocities. Thus, it is straightforward to apply Reynolds flux calculations, similar to the benthic oxygen flux estimates discussed in this issue by Berg 
and Huettel, to the turbulent diffusion of fine sediment (Fugate and Friedrichs, 2002; see Figure 1 in Berg and Huettel, this issue, for a photo of an example acoustic velocimeter).

Assuming a local balance for sediment suspension between downward settling by gravity and upward turbulent transport by Reynolds flux yields

$$
<\mathrm{C}>\mathrm{w}_{\mathrm{s}}=\left\langle\mathrm{C}^{\prime} \mathrm{w}^{\prime}\right\rangle
$$

where $\mathrm{C}$ is suspended sediment mass concentration, $\mathrm{w}_{\mathrm{s}}$ is sediment settling velocity, and $w$ is vertical water velocity. Within a few tens of centimeters of the bed, this balance commonly holds to within $1-10 \%$ at temporal scales as short as a few minutes. Angle brackets in Equation 1 indicate a time average over a sampling burst lasting on the order of minutes, and primes indicate fluctuations away from the burst average. Because small current meters such as the acoustic Doppler velocimeter (ADV) can measure both $\mathrm{C}$ and $\mathrm{w}$, including turbulent fluctuations, one can use the slope of $\langle\mathrm{C}\rangle$ vs. $\left\langle\mathrm{C}^{\prime} \mathrm{w}^{\prime}\right\rangle$ to estimate burst-averaged values of $\mathrm{w}_{\mathrm{s}}$ (Fugate and Friedrichs, 2002).

Figure 1(a)-(c) displays time series of acoustically derived bed elevation, sediment concentration, and settling velocity from the York River estuary, Virginia, with $\mathrm{w}_{\mathrm{s}}$ estimated by fitting Equation 1 to consecutive 3.5-day periods, each containing hundreds of ADV sampling bursts. Pump samples were used to calibrate ADV backscatter for total suspended solids, and $\langle\mathrm{C}>$ was regressed against $\left\langle\mathrm{C}^{\prime} \mathrm{w}^{\prime}\right\rangle$ every 3.5 days to produce a time series of best-fit $w_{s}$. Observations
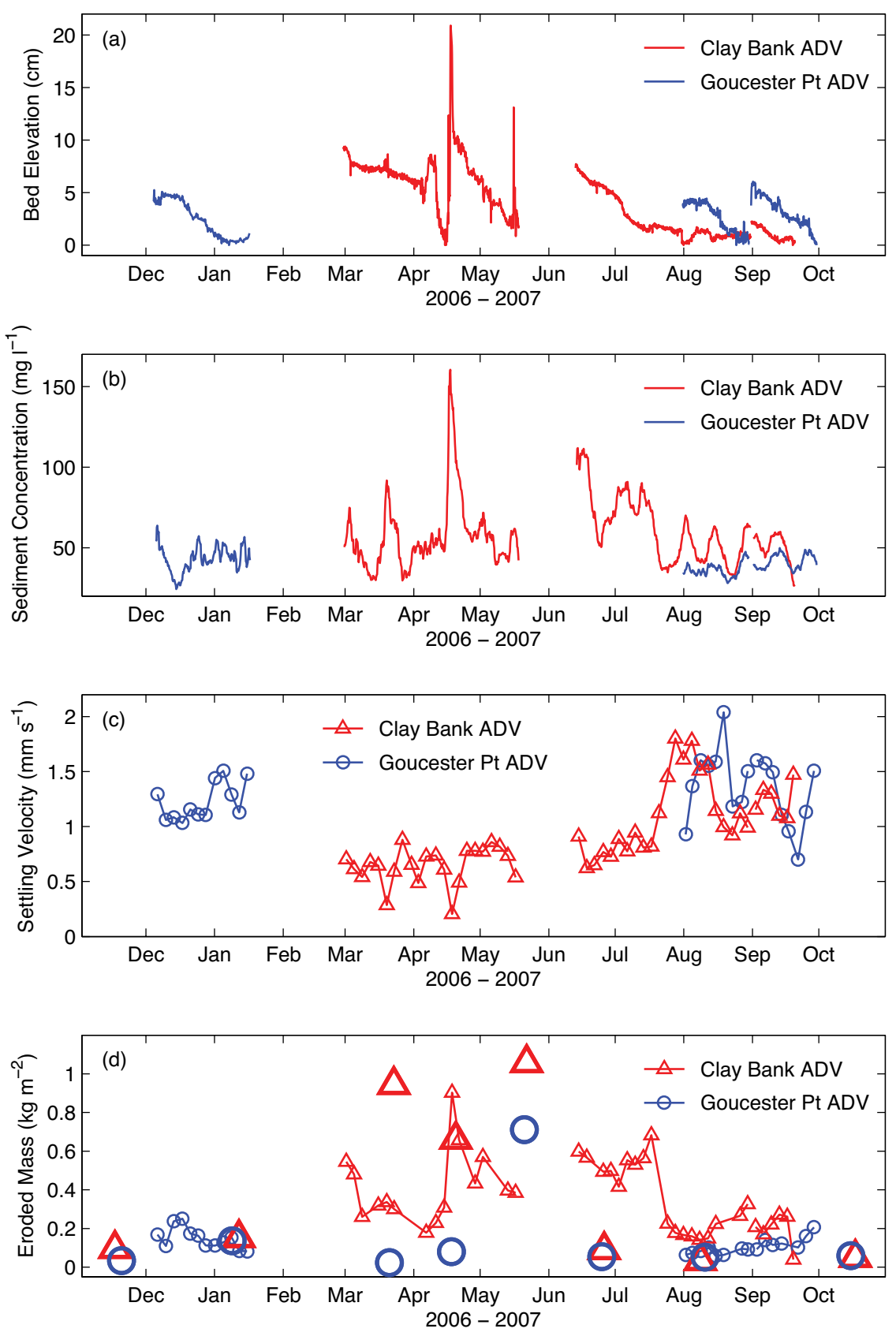

Figure 1. Acoustic Doppler velocimeter (ADV) time-series from the York River estuary of (a) seabed elevation (relative to the lowest elevation recorded during each deployment), (b) tidally averaged suspended sediment concentration, (c) sediment settling velocity, and (d) eroded mass at a bed stress of $0.2 \mathrm{~Pa}$. The ADV sensing volume was approximately $35 \mathrm{~cm}$ above the bed ( $18 \mathrm{~cm}$ below the acoustic transmitter). The water depth is $8 \mathrm{~m}$ at Gloucester Point and $6 \mathrm{~m}$ at Clay Bank. Estimates of erodibility from Dickhudt (2008) for adjacent sites based on a Gust Microcosm are shown in (d) by the larger corresponding symbols. 
suggest that more slowly settling $\left(\mathrm{w}_{\mathrm{s}} \approx 0.5 \mathrm{~mm} \mathrm{~s}^{-1}\right)$ muddy sediment dominated the Clay Bank region of the estuary in spring in association with higher sediment concentrations and greater fluctuations in bed elevation. In contrast, more rapidly settling, presumably more pelletized sediment $\left(\mathrm{w}_{\mathrm{s}} \approx 1-1.5 \mathrm{~mm} \mathrm{~s}^{-1}\right)$ dominated both Clay Bank and Gloucester Point in the late summer during a period of lower sediment concentration and less change in bed elevation.

The York River estuary was chosen for MUDBED in part because of the strong spatial and temporal gradients found there in the influence of biological versus physical processes on benthic exchange (Schaffner et al., 2001; Fugate and Friedrichs, 2003). Bioturbation and biological aggregation of fine sediment tends to be more important near the mouth of the estuary (in the vicinity of Gloucester Point), whereas physical reworking of the bed and turbulenceinduced particle breakup tend to be more dominant in the central estuary (near Clay Bank). The strong gradients in seabed processes found over a few tens of kilometers along the York River estuary provide a logistically attractive analogy to similar gradients found on muddy shelves, such as those of the

Carl T. Friedrichs (cfried@vims.edu) is Professor, Virginia Institute of Marine Science, College of William andMary, Gloucester Point, VA, USA. Grace M. Cartwright is Marine Scientist Senior, Virginia Institute of Marine Science, College of William and Mary, Gloucester Point, VA, USA. Patrick J. Dickhudt is Marine Scientist, Virginia Institute of Marine Science, College of William and Mary, Gloucester Point, VA, USA.
East China Sea (Rhoads et al., 1985). In addition, Dickhudt (2008) observed that mobile pools of easily suspended mud in the York River tend to move down estuary following periods of high river discharge. Using a small erosion flume known as a Gust microcosm, Dickhudt (2008) documented a significant increase in bed erodibility at Clay Bank following the 2007 spring freshet (Figure 1d).

Output from ADVs can also provide an indirect measure of bed erodibility, because the ADV documents both bottom stress $\left(\tau_{b}\right)$ and suspended sediment concentration (C). Traditionally, in situ bed erodibility is determined by applying controlled stresses to the bed and recording the amount of material suspended, either by lowering a flume to the seabed or by applying a smaller flume to seabed cores in a boat- or land-based lab immediately after sample collection (Sanford, 2006). The greater the suspended mass in response to a given applied stress, the greater the erodibility. Although the ADV cannot control stress, a bottommounted ADV still documents stress via $\tau_{b}=-\rho\left\langle u^{\prime} w^{\prime}\right\rangle$, where $\rho$ is fluid density, and $u^{\prime}$ and $w^{\prime}$ are turbulent fluctuations in horizontal and vertical velocity. Estimating the vertical integral of $\mathrm{C}$ during a period of slowly increasing current speed then gives an estimate of eroded mass as a continuous function of $\tau_{b}$.

Close to the bed, a reasonable approximation for the vertical variation in suspended sediment concentration above and below an ADV mounted at height $\mathrm{z}_{\mathrm{o}}$ is given by the Rouse profile in the form of a power law (e.g., van Rijn, 1993):

$$
\mathrm{C}=\mathrm{C}_{\mathrm{o}}\left(\mathrm{z} / \mathrm{z}_{\mathrm{o}}\right)^{-\mathrm{P}}
$$

where $\mathrm{C}_{\mathrm{o}}$ is the observed sediment concentration at the $\mathrm{ADV}$, and the Rouse parameter $\mathrm{P}=2.5 \mathrm{w}_{\mathrm{s}}\left(\tau_{\mathrm{b}} / \rho\right)^{-1 / 2}$. Although there are several simplifying assumptions inherent in Equation 2, including nearly steady flow, settling velocity independent of $\mathrm{z}$, no sediment-induced stratification, and the presence of a logarithmic velocity layer, a simple vertical integration of Equation 2 can still provide a rough estimate of eroded mass, M:

$$
\mathrm{M}=\mathrm{z}_{\mathrm{o}} \mathrm{C}_{\mathrm{o}}(1-\mathrm{P})^{-1}\left(\mathrm{~h} / \mathrm{z}_{\mathrm{o}}\right)^{1-\mathrm{P}}
$$

where $h$ is the height of the integration.

For each 3.5-day period examined in Figure 1c, Equation 3 was used to produce a scatter plot of eroded mass versus bed stress. A best-fit linear regression every 3.5 days was then used to estimate the eroded mass characteristic of a typical peak tidal stress of $0.2 \mathrm{~Pa}$. Figure $1 \mathrm{~d}$ displays the resulting eroded mass interpolated or extrapolated to $0.2 \mathrm{~Pa}$ as a function of time, assuming $\mathrm{h}=4 \mathrm{~m}$, discarding 3.5-day periods where $\tau_{\mathrm{b}}$ never exceeded $0.1 \mathrm{~Pa}$, and subtracting the wash-load (the minimum observed concentration during each period) from $\mathrm{C}_{\mathrm{o}}$. Observations suggest that relatively high bed erodibilities (i.e., large values of $\mathrm{M}$ for a given $\tau_{b}$ ) often occur at Clay Bank in the spring, whereas erodibilities are lower at both Clay Bank and Gloucester Point in the late summer.

Seasonal variations in bed erodibility derived from the ADV analysis are roughly consistent with those observed directly by Dickhudt (2008) using a Gust microcosm applied to cores collected within a few hundred meters of the ADV tripods. Based on core sampling, Dickhudt (2008) concluded that lower erodibility is consistent with “equilibrium" biological processing, whereas higher erodibility is characteristic of episodic springtime deposition 
following high river discharge (Figure 2). Continual ADV measurements support this general pattern and further link reduced settling velocity to high erodibility and recent deposition (as suggested by fluctuating bed elevation).

Discrepancies between ADV and microcosm-derived erodibilities at shorter time scales may be due to unresolved, small-scale spatial heterogeneity.

The long-term deployment of small, resilient acoustic current meters in fine sediment environments allows the simultaneous, noninvasive observation of suspended sediment concentration, seabed elevation, bed erodibility, and suspended sediment settling velocity under widely varying intensities of bottom stress, deposition, erosion, and biological reworking. Since August 2007, ADVs have been deployed almost continuously at both MUDBED sites, documenting temporal and spatial gradients in the forcing of muddy benthic exchange. As part of MUDBED, we are in the process of implementing real-time data streams from both of these tripods, enhancing the effectiveness of rapid response sampling following events. In energetic environments, deposition and consolidation of $\mathrm{O}$ (1 to 10)-cm-thick muddy beds may occur over time scales of days to a week or two, potentially limiting the effectiveness of preplanned periodic coring. Long-term, continual estimates of changing sediment settling velocity and bed erodibility, as demonstrated here, provide an excellent opportunity to advance our knowledge of the dynamics that control these important parameters. Identification of the alternation between a biologically mediated background state and episodic changes associated with rapid deposition provide an example of

After period of high river flow

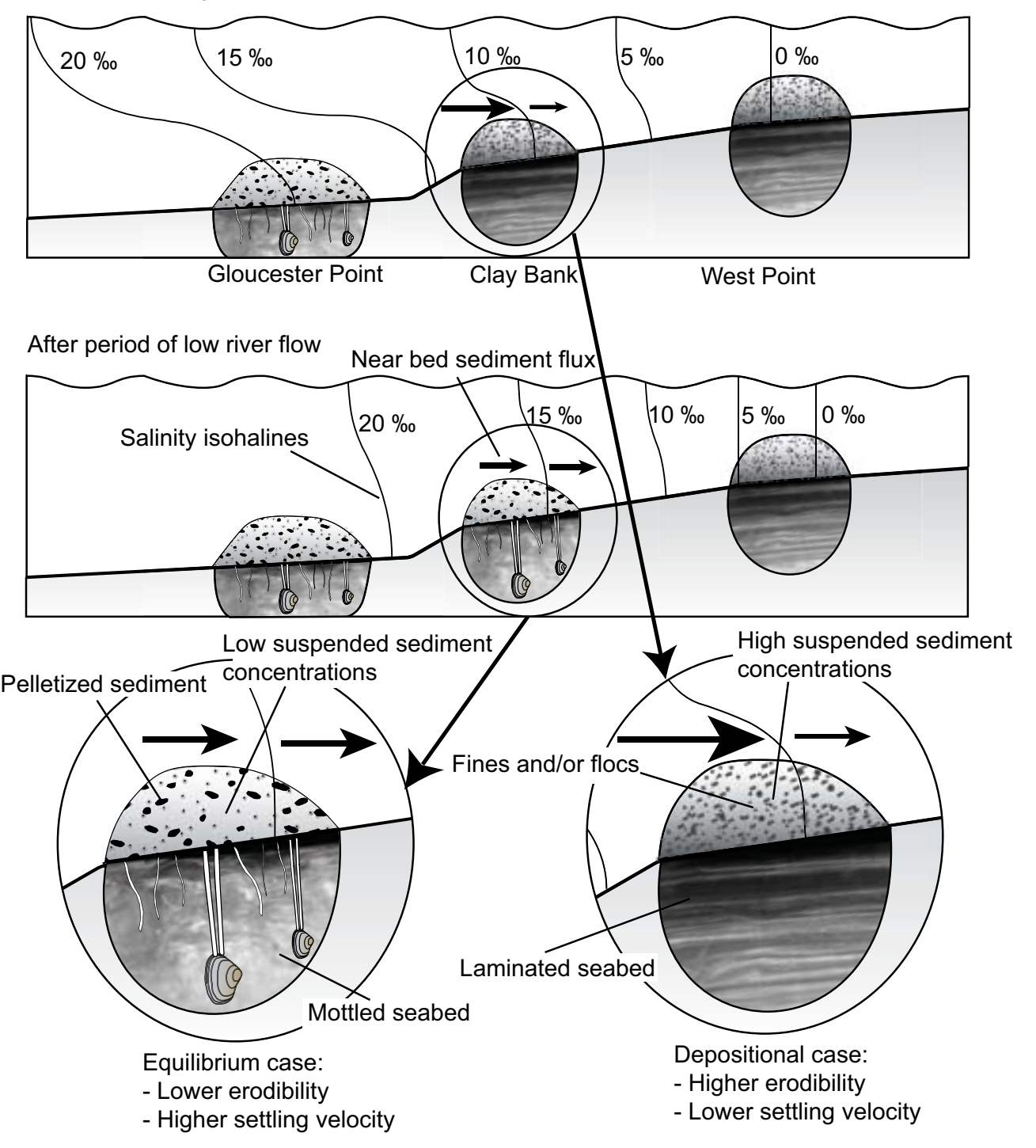

Figure 2. Conceptual model for sediment transport in the York River estuary, including changes in seabed structure and patterns of erodibility and settling velocity in the Clay Bank region of the middle estuary as a function of river flow. The distance from Gloucester Point to West Point is about $45 \mathrm{~km}$. Figure reproduced with permission from Dickhudt (2008)

such an advancement.

Extending our ability to observe fine sediment settling velocity and seabed erodibility using acoustic current meters is only one aspect of the MUDBED project. Co-principal investigators on the larger project include R. Diaz, C. Harris, S. Kuehl, J. McNinch and L. Schaffner at the Virginia Institute of Marine Science, and L. Sanford at the University of
Maryland Center for Environmental Science. Other supporting technologies being deployed by MUDBED participants include laser in situ scattering and transmissometry (LISSTs), video settling tubes, digital x-radiography, seabed profile cameras, and high-frequency Chirp and rotating side-scan sonar. The LISSTs and settling tubes provide more direct measures of particle size and settling 
velocity, while $\mathrm{x}$-radiography, seabed cameras, and sonar help constrain biological and physical influences on the seabed. In addition, a complementary three-dimensional sediment transport model is being developed for the York River estuary that includes time-varying bed consolidation. Preliminary results from three-dimensional modeling (Rinehimer, 2008) largely support the conceptual model for the York River estuary presented in Figure 2.

\section{ACKNOWLEDGMENTS}

The MUDBED Project is supported by National Science Foundation grants OCE-0536572 and OCE-0536466. This is Contribution No. 2976 of the Virginia Institute of Marine Science, The College of William and Mary. 囵

\section{REFERENCES}

Dickhudt, P.J. 2008. Controls on Erodibility in a Partially Mixed Estuary: York River, Virginia. MS Thesis, School of Marine Science, College of William and Mary, Gloucester Point, VA.

Dyer, K.R., J. Conrelisse, M.P. Dearnaley, M.J. Fennessy, S.E.Jones, J. Kappenberg, I.N. McCave, M. Pejrup, W. Puls, W. Van Leussen, and K. Wolfstein. 1996. A comparison of in situ techniques for estuarine floc settling velocity measurement. Journal of Sea Research 26:15-29.

Fugate, D.C., and C.T. Friedrichs. 2002. Determining concentration and fall velocity of estuarine particle populations using ADV, OBS and LISST. Continental Shelf Research 22:1,867-1,886.

Fugate, D.C., and C.T. Friedrichs. 2003. Controls on suspended aggregate size in partially mixed estuaries. Estuarine Coastal and Shelf Science 58:389-404.

Harris, C.K., P. Traykovski, and W.R. Geyer. 2005. Flood dispersal and deposition by near-bed gravitational sediment flows and oceanographic transport: A numerical modeling study of the Eel River shelf, northern California. Journal of Geophysical Research 110(C09025), doi:10.0129/2004JC002727.

Holdaway, G.P., P.D. Thorne, D. Flatt, S.E. Jones, and D. Prandle. 1999. Comparison between ADCP and transmissometer measurements of suspended sediment concentration. Continental Shelf Research 19:421-441

Lee, H.J., and P.L. Wiberg. 2002. Character, fate, and biological effects of contaminated, effluent-affected sediment on the Palos Verdes margin, southern California: An overview. Continental Shelf Research 22:835-840.

McKee, B.A., R.C. Aller, M.A. Allison, T.S. Bianchi, and G.C. Kineke. 2004. Transport and transformation of dissolved and particulate materials on continental margins influenced by major rivers: Benthic boundary layer and seabed processes. Continental Shelf Research 24:899-926.

Rhoads, D.C., D.F. Boesch, T. Zhican, X. Fengshan, H. Liqiang, and K.J. Nilsen. 1985. Macrobenthos and sedimentary facies on the Changjiang delta platform and adjacent continental shelf, East China Sea. Continental Shelf Research 4:189-213.

Rinehimer, J.P. 2008. Sediment Transport and Erodibility in the York River Estuary: A Model Study. MS Thesis, School of Marine Science, College of William and Mary, Gloucester Point, VA.

Sanford, L.P. 2006. Uncertainties in sediment erodibility estimates due to a lack of standards for experimental protocols and data interpretation. Integrated Environmental Assessment and Management 2:29-34.

Schaffner, L.C., E.K. Hinchey, T.M. Dellapenna, C.T. Friedrichs, M. Thompson Neubauer, M.E. Smith, and S.A. Kuehl. 2001. Physical energy regimes, sea-bed dynamics and organism-sediment interactions along an estuarine gradient. Pp. 161-419 in: Organism-Sediment Interactions, J.Y. Aller, S.A. Woodin, and R.C. Aller, eds, University of South Carolina Press, Columbia, SC.

Van Rijn, L.C. 1993. Principles of Sediment Transport in Rivers, Estuaries and Coastal Seas. Aqua Publications, Amsterdam, 415 pp. 